\title{
RESENHA: Migrant Belongings. Memory, Space, Identity
}

\author{
Joana Miranda \\ Universidade Aberta/Centro de Estudos das \\ Migrações e das Relações Interculturais \\ joana@uab.pt
}

FORTIER, Anne-Marie Migrant Belongings. Memory, Space, Identity. Oxford/Nova Iorque: Berg Publishers, 2000, 209 p.

Apesar da primeira edição de Migrant Belongings. Memory, Space, Identity de Anne-Marie Fortier ter sido publicada em 2000 e de, desde então, terem sido significativas as transformações, quer a nível da dinâmica dos movimentos migratórios europeus, quer a nível do state of the art da discussão teórica sobre identidades e, em particular, sobre a fecunda articulação identidades-migrações-género, este livro constitui uma referência incontornável da literatura na área pelos importantes contributos que trouxe à reflexão teórica e metodológica.

Fortier leciona atualmente na Universidade de Lancaster e está ligada a vários centros de investigação: Centre for Gender and Women's Studies, Centre for Mobilities Research (CeMoRe), Centre for Transcultural Writing and Research e Mobilities.Lab. Os seus interesses académicos situam-se nas áreas dos estudos raciais críticos, estudos de género e da sexualidade, estudos culturais, pós-colonialismo, multiculturalismo e formação da nação, estudos migratórios críticos, estudos de diáspora e políticas culturais das emoções.

$\mathrm{O}$ contributo de Fortier para o debate na área poderá ser descrito como pós-estruturalista, feminista pós-colonial/queer e tem em conta os intercruzamentos das dimensões género, sexualidade, geração e 'raça' nas respostas da nação e do estado às migrações.

Para além deste livro que aqui apresentamos, a autora conta com publicações mais recentes na área do multiculturalismo (Multicultural Horizons. Diversity and the limits of the civil nation, Routledge, 2008) e da cidadania (em particular da cidadania afetiva) e migração ((2010), "Proximity by design? Affective citizenship and the management of unease", Citizenship Studies, 14(1) p. 17-30).

Atualmente Fortier faz investigação sobre o processo de naturalização da cidadania no Reino Unido.

O processo produtivo do livro desenvolveu-se em três estádios (sendo o primeiro deles a produção da tese de doutoramento de Fortier) e em três lugares distintos (Londres, Montreal e Lancaster) e o seu objeto de análise são as pertenças migratórias italianas em Inglaterra na década de noventa do século XX, discutindo-se a forma como a experiência de movimento migratório e de recomeço pode ser formativa, sendo o foco de análise as práticas institucionais e não as experiências identitárias individuais.

Por oposição ao isomorfismo do lugar, espaço e cultura bem como à reificação do desenraizamento como figura paradigmática da vida pós-moderna, Fortier preocupa-se com a forma como a identidade cultural é desterritorializada e reterritorializada, com o esforço dos indivíduos para criarem espaços comuns de pertença baseados na reprodução de tradições, partindo sempre do pressuposto de que as comunidades estão sempre ligadas a lugares reais ou imaginados (Gupta e Ferguson, 1992).

A pertença é perspetivada pela autora como o é por Elspeth Probyn (1996) que desloca a identidade do seu estado fundacional, referindo-se a pertença em vez de a identidade, por considerar que a primeira capta mais adequadamente o desejo de algum tipo de ligação a pessoas, lugares ou modos de ser.

Relevante para Fortier é, igualmente, o conceito de Probyn (1996) de mundo social enquanto uma superfície, de identidade como um limiar, uma localização que, por definição, enquadra a passagem de um espaço para outro, de identidade como uma transição, produzindo-se como o processo combinado de ser e de se tornar.

Mas enquanto que Probyn adota uma perspetiva Deleuziana que enfatiza o movimento, Fortier encara as pertenças migratórias como constituídas com base em movimento e em ligação.

Incluída na formação da pertença, a identidade é uma posicionalidade momentânea (Hall, 1996) que está sempre a tornar-se; as pertenças migratórias constituem uma tensão produtiva resultante da articulação entre o movimento e a ligação, a sutura e a partida, o exterior e o interior na formação da 
identidade.

A 'diferença' é posicionada no interior da lógica de análise e não é incorporada como uma adição inorgânica (di Leonardo, 1991) sendo, pois, a identidade um processo que produz quer semelhança quer diferença.

A autora procura compreender como o género e a etnicidade circulam, se articulam, estão inscritos e produzem representações da identidade coletiva e da particularidade local.

Fortier pretende afastar-se de uma economia de identidade/diferença assente na lógica matemática de adições e subtrações (Judith Butler, 1993), não colocando todos os níveis de diferenciação social ao nível de um campo de jogos (como Sara Ahmed notou em 1998).

Muita da concetualização teórica alicerça-se em Judith Butler e na sua teoria performativa da linguagem. Para esta filósofa americana pósestruturalista a performatividade é, antes de mais, sobre situacionalidade (Butler, 1993). É através da invocação da convenção que os atos auferem o seu poder de ligação, é através da reiteração de normas que precedem, constrangem e excedem $\mathrm{o}$ ator. A performatividade da identidade não diz apenas respeito a rotina ou a reiterações de práticas no contexto de vidas individuais.

$\mathrm{Na}$ introdução do livro, para além da reflexão sobre as influências teóricas do seu trabalho, Fortier desenvolve uma análise do processo de conhecimento, salientando que o 'trabalho do conhecimento' não advém do nada e que o produtor deste 'conhecimento situado' (Haraway, 1991) não está escondido e não é invisível (Skeggs, 1997).

O trabalho de campo resultou das interacções da investigadora com os homens e com as mulheres da Igreja Italiana de St. Peter e do Centro Scalabrini em Londres e do contato da autora com um conjunto de atividades da comunidade italiana residente na cidade. A metodologia utilizada incluíu observação participante, entrevistas semi-diretivas e análise de um vasto conjunto de documentos escritos.

$\mathrm{O}$ que se pretende entender, de acordo com o explicitado pela própria autora, é a identidade nas suas diversas dimensões, não chegar a uma noção transparente de identidade, não a um texto acabado mas, antes, aos limites, limiares, tensões, descontinuidades, contradições e estratégias de coerência e de estabilização envolvidas na formação da identidade italiana em Londres.

O livro é constituído por seis capítulos. Vejamos o que cada um deles trata.

No capítulo 1 - Situating the Italian project of visibility - Fortier situa o projeto de identidade italiana num contexto histórico e teórico mais vasto. Neste capítulo é identificado o ponto de partida do estudo e esboçadas as suas conexões com os discursos teóricos recentes sobre diásporas. Fortier avalia criticamente as tentativas de diferenciar as temáticas das migrações (diásporas, imigrantes, grupos étnicos,...) e argumenta que a utilização de 'diáspora' constitui um instrumento heurístico mais do que uma categoria descritiva.

No capítulo 2 - Imaginning a community: migration, settlement, sacrifice and the trope kinship tem lugar a procura de testemunhos da presença italiana em Inglaterra, os quais são discutidos no âmbito do projeto mais vasto da memória $\mathrm{e}$ recuperação coletiva. Os textos são escritos por italianos e constituem exemplos na criação de uma comunidade imaginada, proporcionando uma solução parcial para o caráter fluido da coletividade italiana, legitimando as acções desenvolvidas para criar uma identidade grupal italiana.

O capítulo 3 - The politics of 'Italians abroad': nation, diaspora and new geographies of identity centra-se nas políticas de identidade dos, na altura, líderes das comunidades imigrantes italianas em Londres. Examina-se um conjunto de práticas da nação (debates políticos, cerimónias de estado, concursos de beleza,...), procurando revelar o tipo de 'comunidade' e de 'cidadãos' que as mesmas representam.

O capítulo 4 - Space, place and icons: creating 'habitual spaces' - explora o posicionamento do Centro Scalabrini de Londres face ao caráter mutável da emigração. O centro é analisado como um espaço em que coexistem diferentes formas de sociabilidade que complexificam as suas pretensões universalistas, sendo analisado o tipo de 'mulher italiana' que o 'clube das mulheres' do centro promove.

No capítulo 5 - Re-membering places and the performance of belonging - são analisados episódios de vida na igreja de St. Peter. As atividades são essencialmente acerca de rememorar: a formação de corpos individuais e coletivos que são chamados a habitar a igreja e os seus arredores. O rememorar está ligado à memória, à localização e ao corpo no processo de povoar os terrenos italianos da pertença.

O capítulo final - Conclusion: Memory, location and the body motions of duration - retoma os resultados da investigação, examinando as implicações da teorização da identidade e da cultura nas pertenças migrantes.

Concluindo: Ainda que este não seja um dos livros mais recentes na área de investigação em que se situa, é um livro de leitura recomendada pela densidade e coesão do discurso, sempre assente numa tessitura concetual de grande riqueza e pela fluidez da narrativa,

Joana Miranda 
RESENHA: Migrant Belongings. Memory, Space,

Identity

decerto inspiradora de incursões criativas pelas áreas em análise.

\section{Referências}

AHMED, Sara. Differences that matter. Feminist theory and Postmodernism. Cambridge: Cambridge University Press, 1998.

BUTLER, Judith. Bodies that matter. On the discursive limits of "Sex". Nova Iorque e Londres: Routledge, 1993.

DI LEONARDO, Micaela. "Introduction. Gender, culture and political economy: Feminist Antrophology in historical perspective". DI LEONARDO, Micaela. (Ed.). Gender at the Crossroads of knowledge: Feminist Antrophology in the postmodern era. Berkeley: University of California Press, 1991.

GUPTA, Akhil. \& FERGUSON, James. "The song of the nonaligned world: Transnational identities and the reinscription of space in late capitalism". Cultural Antrophology v.7 n.1. P 63-77, 1992.

HALL, Stuart. "Introduction. Who needs identity?". HALL, Stuart \& DU GAY, Paul (Eds.). Questions of cultural identity. Londres: Sage, 1996.

HARAWAY, Donna. Simians, cyborgs and women. The reinvention of nature. Londres: Free Association Books, 1991.

PROBYN, Elspeth. Outside belongings. Nova Iorque e Londres: Routledge, 1996.

SKEGGS, Beverley. Formations of class and gender. Londres: Sage, 1997. 